\title{
Contraceptive Utilization and Unmet Need for Contraception Among Women Undergoing Treatment for Tuberculosis in Addis Ababa, Ethiopia; a Cross-sectional Study.
}

Semaria Solomon Alemayehu ( $\nabla$ semariasol@gmial.com )

St.Paul's Hospital Millennium Medical College https://orcid.org/0000-0002-7412-9400

Berhanu Yitayew

Debre Brehan University

Abebaw Kebede

Ethiopian Public Health Institute

Haileyesus Getahun

Global TB Program, WHO

\section{Research Article}

Keywords: TB, Contraceptive, Unmet need

Posted Date: May 13th, 2021

DOl: https://doi.org/10.21203/rs.3.rs-513918/v1

License: (c) (i) This work is licensed under a Creative Commons Attribution 4.0 International License.

Read Full License 


\section{Abstract}

Introduction: Pregnancy can pose a risk to women on tuberculosis (TB) treatment with a threat to the mother, fetus, and family at large. Contraceptive counseling and provision should be an integral part of TB clinics. Physiological and stress-related effects result when pregnancy occurs on TB illness and while treatment. Hence, this study aimed to assess contraceptive utilization, unmet need among women on TB treatment, and integration of family planning (FP) services with TB clinics in Addis Ababa, Ethiopia.

Methods: A facility-based cross-sectional study was conducted using an interviewer-administered questionnaire. A total of 316 women aged 18-49 who were on TB treatment were recruited from one TB referral hospital and five randomly selected health centers in Addis Ababa with a response rate of $100 \%$. The contraceptive utilization rate, unmet need, and integration of FP and TB services were determined. Logistic regression models were conducted to identify factors associated with contraceptive utilization.

Result: Among women on TB treatment 49 (41.9\%) were using contraceptives. Out of contraceptive users, 10 (34.5\%) used contraceptive to limit and 18 (62.1\%) used to space. In multiple logistic regression only parity had a significant association with contraceptive utilization. Women who had 1-3 children had 0.351 odds of having used contraception than those who had no children (AOR=0.351, 95\% $\mathrm{Cl} 0.152$, $0.815, p=0.001)$. Among women who were married or sexually active, $12(18.9 \%)$ had an unmetneed. Of the study participants, 144 (45.6\% )have been informed about FP services at the TB clinics.

Conclusion: The contraceptive utilization rate of women in the current study is slightly higher than the national prevalence yet it is still very low. Furthermore, the unmet need was lower than the national report for the general population However, more attention should be given to raise awareness of utilization in this group. Educating women about the risk of getting pregnant while visiting the health facility for TB medication will help improve their chances of better recovery, avoid medication side effects on the fetus, and improve their quality of life. TB guidelines can consider providing FP couselings when initiating treatment to provide women with the power of information to make deliberate decisions.

\section{Background}

Tuberculosis (TB) often affects the young productive and fertile segment of society (1). Furthermore, if pregnancy occurs with TB, it has serious maternal and neonatal complications including increased risk of maternal morbidity, cesarean delivery, preterm birth, low birth weight, and as well as perinatal death (2). Likewise, tuberculosis is listed among the conditions associated with increased risk for adverse health events as a result of pregnancy (3). Pregnant women with active TB should be treated, even in the first stage of pregnancy. Although the first-line drugs used in the initial treatment regimen for TB cross the placenta, they do not appear to have harmful effects on the fetus. The problem is pronounced if the mother develops Multi-Drug Resistance-Tuberculosis (MDR-TB) in which the regimens become more toxic. Drugs such as Streptomycin, Kanamycin, Amikacin, Capreomycin, and Fluoroquinolones are contraindicated during pregnancy (4). Globally in 2011, 216,500 active TB cases were reported among 
pregnant mothers of which the majority were in Africa and Southeast Asia (5). However sufficient data is lacking on the exact numbers of women getting pregnant while on TB medication.

Family planning (FP) is a means of providing safe motherhood and reproductive right which has an important role in preventing unwanted pregnancy and reducing fertility rate (6). Similarly, women identified as having an unmet need include those who express a desire to postpone their next birth for more than two years (spacing) as well as those who wish to have no more children (limiting) (7). There should be special provisions made for women planning to bear children while on TB treatment with counseling of the risks involved of the two occurring together. This involves providing her all the existing evidence to help her make informed decisions. A high risk patient may prefer to either avoid pregnancy altogether to enhance her health or delay pregnancy until therapy is completed (3). Further research is required for women on TB treatment around appropriate service delivery means to assess, integrate, and enhance uptake of FP services among clients.

There is a data gap in Ethiopia so far on the use and unmet need for contraception among TB patients. Assessing the unmet demand for FP methods among women and addressing the need is a critical element in enabling the sexual and reproductive rights of TB patients. This will also enable synergy between communicable diseases and reproductive and sexual health services. We aim to assess the contraceptive utilization, unmet need, and integration of FP in TB clinics among women on TB treatment.

\section{Methods}

A cross-sectional study was conducted at five health centers (HCs) and one TB referral hospital (St. Peter's TB Specialized Hospital) in Addis Ababa, Ethiopia from March to November 2016. Addis Ababa is the capital city of Ethiopia located $2400 \mathrm{~m}$ above sea level. It has a total population of 4,793,699 according to the 2020 World Population Review (8). At the time of the study, there are $47 \mathrm{HCs}$ and 41 public and private hospitals. St. Peter's TB Specialized Hospital is the only public TB referral hospital in the city and was purposefully included for the study whereas the HCs were selected by systematic random sampling of every $10^{\text {th }} \mathrm{HC}$ based on alphabetical ordering among all the existing $\mathrm{HCs}$ in each Sub-city of Addis Ababa. Study participants were women on TB treatment in the TB clinics within the reproductive age group (18 - 49 years). The sample size was determined using the standard formula for sample size determination taking 29\% Contraceptive Prevalence Rate (CPR) of the 2011 EDHS report, $95 \%$ confidence interval, and a precision of $5 \%$. A random sampling technique was used to select study participants from the registry of patients on TB treatment at the treatment centers that had bacteriologically confirmed TB diagnosis. All women coming to the TB treatment were approached to attain a total of 316 patients with the standard formula for sample size calculation.TB confirmed women of reproductive age were included in the current study with a response rate of $100 \%$ from March to November 2016. Data were collected using structured questionnaires that were pretested and validated. The questionnaire was developed in English and translated into the local language (Amharic) and translated back to English to check for consistency. The questionnaires were pretested in the same participants to avoid measurement errors. Data were collected by nurses trained on the purpose of the 
study and on how to administer and complete the questionnaire verbally (that took about 8 minutes on average to complete). After the explanation of the purpose of the study, participants provided signed informed consent to participate and were enrolled when they come to HCs for TB medication by the data collectors. Institutional Review Board (IRB) approval was obtained from SPHMMC and communicated with a permission letter to each study site.

The data were entered into Epi Info version 7 and exported to SPSS version 20 software for analysis. Frequencies and cross-tabulations were used to summarize descriptive statistics of the data and tables and graphs were used for data presentation. Univariate logistic regression was used primarily to check for variables that have an association with the dependent variable individually. Furthermore, variables were entered into multiple logistic regressions for controlling the possible effect of confounders and finally, the variables which had a significant association with contraceptive utilization were assessed by using OR with $95 \% \mathrm{Cl}$. Variables with a p-value of less than or equal 0.05 in the multivariate analysis were considered to have a significant association with contraceptive utilization. Modern contraceptive utilization is defined as a product or medical procedure that interferes with reproduction from acts of sexual intercourse excluding the traditional, natural, and physiological methods (9). Modern contraceptive utilization in this study was defined as the percentage of women currently using any of these methods of contraception among all women (i.e., those aged 18 to 49) who are married, in a union, and sexually active single women. Similarly, the in-union group includes women living with their partner in the same household and who are not married according to the marriage laws or customs of a country. While the unmet need is taken to be the percentage of married, in-union, single, and sexually active women of reproductive age who want to stop or postpone childbearing but who report that they are not using any method of contraception to prevent pregnancy.

\section{Result}

\section{Socio-demographic Characteristics of women on TB treatment in Addis Ababa, Ethiopia}

A total of 316 TB confirmed women of reproductive age were included in the current study. The median age of the respondents was $28 \pm 6.839$. The majority of women were from urban areas (81.3\%). About $51.8 \%$ had secondary education or higher and $23.6 \%$ had elementary education. The average monthly income was about 782 birr per month with a $54.4 \%$ unemployment rate. The majorities $(55.1 \%)$ of the participants were single and $29.4 \%$ were married, the remaining were separated, divorced, or widowed. Of the total, at the time of the study, $71.5 \%$ were not in a union. Among the study participants, $62 \%$ had no children, while $30.7 \%$ had one to three children. During the data collection, $5(1.6 \%)$ were pregnant. The rest were not pregnant $(97.8 \%)$ or not confirmed (undecided) $(0.6 \%)$ (Table 1$)$.

\section{Contraceptive Utilization of women on TB treatment in Addis Ababa, Ethiopia}

The utilization of contraceptives among women on TB treatment was $41.9 \%, 95 \% \mathrm{Cl}$ (32.5-50.4). From the total married women (93), 28 were currently using contraceptives of which 10 (34.5\%) were using to limit by either wanting no more children or wanting later. All the rest 18 (62.1\%), were using to space. The 
majority of contraceptive users were using equally Implant or IUD followed by injection, oral contraceptive, and tubal ligation (Figure I). When participants were asked if they ever used a contraceptive, $32.6 \%$ had used contraceptives previously. Contraceptive utilization among referred rural women was $9(18.8 \%)$. In the univariate logistic regression analysis, age was significantly associated with contraceptive utilization ( $P=0.01)$. Twenty-eight $(32.2 \%)$ married and $17(9.8 \%)$ single women were using contraceptives. Marital status is significantly affecting contraceptive utilization in the univariate logistic regression analysis. Nonetheless, as married women might not be with their partners at the study time due to their TB status, the study participants were divided into two groups, in union and not in a union. It was found that the majority of women in a union were more likely to use modern contraceptive than women who are not currently in a union, 28(33.3\%), and 22 (9.8\%) respectively in univariate logistic regression analysis. Likewise, having 1-3 children was more likely a factor to use modern contraceptives which were $29(31.2 \%)$ with a significant difference observed (Table 1).

In the univariate logistic regression analysis age group, union, parity, knowledge of women where FP services are available, and closeness of FP service providing places had statistically significant associated with modern contraceptive utilization. Taking these factors however, in multivariate analysis, only parity had a statistically significant association with contraceptive utilization (AOR $=0.351,95 \% \mathrm{Cl}$ $(0.152,0.815, p=0.001)$. Women who had $1-3$ children had 0.351 the odds of having used contraception than those who had no children. However, education status, occupation, and monthly income were not statistically significantly associated with contraceptive utilization.

\section{Unmet Need for Contraceptive Utilization among women on TB treatment in Addis Ababa, Ethiopia}

Unmet need for contraceptives was determined among married and sexually active single women.

The prevalence of pregnancy among TB patients was $2 \%$ (6/316). Among married women who were not using contraceptives, 6 women were pregnant or postpartum amenorrheic (period not returned since last live birth in the last 2 years). Four women wanted current pregnancy, while one postpartum amenorrheic woman wanted last birth at that time, making them have no unmet need. There was one pregnant woman who wanted the pregnancy later, making her have an unmet need for spacing. Participants who were not using contraceptives, not pregnant or postpartum amenorrheic were 58 women. There were no infecund women: who were married $5+$ years ago, had no children in the past 5 years, and never used contraception. Thirty-five women were infecund and did not have an unmet need. While there were 23 fecund women of which 11 wanted a child within 2 years while the 12 had unmet contraceptive needs. The unmet need determination included both married and sexually active single women. There were a total of 18 single sexually active women of which 8 were using contraceptives. The prevalence of unmet need in the current study was found to be $18.9 \%$ (Figure II) according to the revised unmetneed calculations (10). No variable was significantly associated with the unmet need among women on TB treatment.

\section{Family Planning Services in TB Clinic}


During their TB treatment, 144 (45.6\%) reported having been told about FP services. All of these were referred for FP services in the health facility. The majority 235 (74.4\%) knew where they can get modern contraceptives and 213 (91\%) of the respondents reported that these places were close to their homes (within a $2 \mathrm{~km}$ radius). Among the 144 women that were informed about FP services during their TB treatment, 26 (18.6\%) were using a contraceptive. This was relatively higher than those who were not informed about FP during anti-TB treatment. Of the women told about FP services at the HC or referred for $\mathrm{FP}$ in the $\mathrm{HC}, 28(20 \%)$ and $23(19.5 \%)$ used contraceptives respectively while 20 and one did not. Nonetheless, there was no significant difference in contraceptive utilization. Out of 213 study participants who knew where to get modern contraceptive, $43(20.2 \%)$ were using contraceptives which is significantly higher than those who didn't know where to get the contraceptive (3 participants). The closeness of FP clinic to home had a significant association $(p=0.017)$ for the utilization of contraceptives in the univariate logistic regression analysis (Table 2).

\section{Discussion}

Many girls and women in developing countries who do not want to get pregnant lack access to contraceptives, information, and services which, for many, will cost them their lives (11). Considering the duration, severity of illness, and treatment effect patients should be well informed before pregnancy during TB treatment. To prevent this there is a platform for FP at the TB clinics. There is limited work on contraceptive utilization studies among women on TB treatment and this report tries to provide information by determining the contraceptive utilization rate, unmet need, and FP services within the TB clinics in Addis Ababa. In this study contraceptive utilization among women was found to be $41.9 \%$ which is slightly lower than the national rate, $36.2 \%$ in the general population (Due to the limited data, it is difficult to directly compare with the general population as these groups are regular seekers of health care during their TB treatment.). However, according to the EDHS of 2016, the general contraceptive rate in Addis Ababa was $50 \%$ (12). For the general population studies in East Africa (40\%), the United Republic of Tanzania (40.6\%) and Madagascar (46\%) reported their figures (13). At least with regular visit of health facility HIV patients on follow-up can be comparable with our finding. Accordingly in Addis Ababa among HIV positive women $40.8 \%$ was reported (14) among those who has similar privileges of visiting HCs, in North Shoa Zone (46.9\%) among married women (15). However, the finding is lower than the world prevalence (64\%), Europe (69\%), Asia (68\%), Northern Africa (53\%), Southern Africa (64\%), Zimbabwe (66\%), Rwanda (53.5\%) and Kenya (57.4\%) (13). Whereas, the CPR is higher than the African continent (33\%), Subsaharan Africa (28\%) among female adolescents (13). This could be due to different health service seeking behavior, socio-cultural inclinations, and differences in the health service delivery system. Similarly, our finding is higher than the prevalence of Gonder and Bahir Dar towns (34.3\%) among street women (16). This could be that street women do not visit HCs more often than women on TB treatments who are visiting HCs daily for Directly Observed Therapy (DOTs). As a result they could have better awareness and practice about FP than other women in the community.

Although a relatively higher percentage of rural residents utilize contraceptives than urban, no significant difference was observed. The high CPR among rural residents might be due to a small number of rural 
participants in the study. The finding is inconsistent with the report by Lakew $Y$ et al. (17). In our study, women from both urban and rural settings visited $\mathrm{HC}$ to get TB treatment having similar access to health services provided by health facilities. As the $2015 \mathrm{UN}$ economics and social affairs report on the type of contraceptives, female sterilization, and IUCD are the two most common methods used by married or inunion women worldwide, $19 \%$ of married or in-union women relied on female sterilization and $14 \%$ used IUCD. Short-term methods are less common, $9 \%$ of women used the pills in, $8 \%$ relied on male condoms and $5 \%$ used injectable (13). Similarly in the current study, the majority of women were equally using IUCD or Implant followed by injection, oral contraceptive, and tubal ligation.

Assessing the reasons why women do not prefer to use FP methods is critical in designing programs that could improve the quality of the service. In the current study, the majority of women reported 'not having sex' is a major factor for not using contraceptives. Similarly in a report by Guttmacher Institute, significant proportions of married women with an unmet need gave exposure-related reasons for nonuse. They believed they were not at risk of getting pregnant, most often either because they were breastfeeding or not having sex frequently. They reported among women who were never married, infrequent sexual activity was by far the most common reason for not using contraceptives (18). On the contrary, other scholars reported that never given birth, religious influence, fear of side effects, and desire to have a child were the main reasons why women are not using contraceptives (15).

Women who had 1-3 children were less likely to use contraceptives. These women might not have reached the maximum birth limit or desire to have another child. This could be for the reason that women who reached the maximum birth limit are more likely to practice sex infrequently or not at all. This finding is in line with unpublished data by Sita S, 2003 who reported women with an ideal family size to have a lower need for FP services. Nonetheless, the finding is inconsistent with the report in North Shoa (15).

Considering age to assess contraceptive utilization, the majority (58\%) were in the age group of 23-33. This is in line with the report by Ashford LS et al. (19), who showed that contraceptive use was higher among women 20-34 years of age. The association of contraceptive utilization and age was insignificant in the multivariant analysis. The majority of women were told about where they can get modern contraceptives during their treatment follow up. Almost all of these were informed about where they can get the service. This shows that the integration of contraceptive services, such as counseling of patients on FP at TB clinics, is a good approach for FP service delivery although a significant difference was not observed. On a study of contraception for high-risk patients, regular counseling might be needed for the women on treatment as they may wish to discontinue methods due to actual or perceived side effects that may be associated with their chronic medical condition, or due to their co-morbidity (3). The closeness of FP service providing places to home was also an important factor for contraceptive utilization. Almost all of the contraceptive user women reported FP outlets were close to their homes. Similarly, the report by Ashford LS et al. showed that contraceptive utilization was higher among women, living within walking distance from a health facility (19). 
Worldwide in $2015,12 \%$ of married or in-union women are estimated to have had an unmet need for family planning. The level was much higher, $22 \%$ in the least developed countries. Many of the latter countries are in sub-Saharan Africa, which is also the region where the unmet need was highest (24\%), double the world average in 2015 (13). In Ethiopia, the unmet need for the general population was 22\% (12). In the current study, the prevalence of unmet need was found to be $18.9 \%$ among married and sexually active single women on TB treatment, this is lower than the general population due difference in the repeated health facility visits among the two groups. In countries such as Kenya, Madagascar, Malawi, and Zambia, a decline in unmet need has corresponded with an increase in FP for the general population (13). In this study too, a high contraceptive utilization (41.9\%) corresponds to a lower unmet need finding.

Nationally unmet need for FP declined from 34\% in 2005 to 25\% in 2011 and 22\% in 2016 (12). According to the 2011 EDHS report, there is variation in unmet need prevalence by region, ranging from a low of $10.6 \%$ in Addis Ababa to $29.9 \%$ in Oromia (20). Our result's discrepancy with the report from Addis Ababa could be attributed to the study's participants were residing in combinations of urban and rural areas (referrals). In Tigray, the unmet need for FP among married reproductive age women was $21.4 \%$ (21), this is higher than our finding as study subjects enrolled were more rural residents and of a married group. However, the current finding is comparable to the UN report among married or in-union women in Africa $22 \%$ and East Africa $24 \%$ (13). Similarly, it was in line with the report from the Amhara region (17.4\%) (22) and Cameron (20.4\%) (23). TB treatment centers can consider their services to identify and address those in need of FP service. This can be upscaled to the different HCs providing TB treatment to address high-risk patients by asking them about their FP preferences at their commencement of treatment benchmarking from HIV patients during their initiation of ART services. Although women on TB treatment were informed about FP services at the TB clinic, there is no formal integration of the two services for follow-up of outcome. However, a women's visit to obtain TB treatment could be a good contact point to inform and provide FP services to providing the best available care and also recording outcomes. Further work needs to focus on filling the data gap on women taking TB medication and their contraceptive needs with regards to providing the right counseling. Drug impacts on the fetus at different points of pregnancy to help the mother informed descision on delaying pregnancy should be explored. The stress and psychological impacts of the pregnancy occurring with TB should be investigated to help protect the mother from pressure.

\section{Conclusion}

The contraceptive utilization among TB patients was $41.9 \%$ which was slightly higher than the national rate. The unmet need (18.9\%) in this study was lower than the national report. Women who had no children were more likely to use contraceptives. There is evidence that while the current focus of FP and reproductive health programs is on supporting the well-being of individuals, meeting an unmet need in collaboration with TB can serve broader agendas such as reducing the pressures of co-occurrences and child and maternal mortality, ultimately reducing population growth on societies that are high-risk patients. 


\section{Limitation Of The Study}

The absence of qualitative data to assess possible barriers of contraceptive utilization in-detail was a limitation. Furthermore, study participants were not grouped based on the type of TB disease (Active or MDR TB as different CPR and unmet need could have been measured among the two groups based on MRD TB patient isolation from family during the treatment period).

\section{Declarations}

\section{Competing Interests}

No author has a financial or other competing interest related to this work.

\section{Funding}

Full financial support of the study was obtained from St. Paul's Hospital Millennium Medical College.

\section{Availability of data and Materials}

Data available from the research undertaking are available with the corresponding author upon reasonable request

\section{Author's Contribution}

SS led the project, performed data analysis, and drafted the manuscript. AK and BY involved in data analysis and manuscript write up. HG developed the idea and reviewed the proposal. All authors read and approved the final manuscript.

\section{Acknowledgment}

St Paul's Hospital Millennium Medical College is acknowledged for providing full funding. Study participants' dedication to the research is appreciated. Abebaw Kebede is supported by a training program from NIH/Fogarty International Center Global Infectious Diseases grant D43TW009127. PrePublication Support Service (PREPSS) supported the development of this manuscript by providing prepublication peer-review and copy editing.

\section{Ethics Approval and Consent to Participate}

The research was ethically approved by St. Paul's Hospital Millennium Medical College and St. Peter Hospital. Signed informed consent was obtained from each participant.

\section{Consent to Publish}

Not Applicable 


\section{References}

1. Say L, Chou D, Gemmill A, Tunçalp Ö, Moller A-B, Daniels J, et al. Global causes of maternal death: a WHO systematic analysis. The Lancet Global Health. 2014;2(6):e323-e33.

2. Sobhy S, Babiker ZOE, Zamora J, Khan KS, Kunst H. Maternal and perinatal mortality and morbidity associated with tuberculosis during pregnancy and the postpartum period: a systematic review and meta-analysis. BJOG: An International Journal of Obstetrics \& Gynaecology. 2017;124(5):727-33

3. Cwiak C, editor Contraception for High Risk Patients. Seminars in Perinatology; 2020: Elsevier.

4. CDC. TB treatment and pregnancy 2020 [updated April 5, 2016. Available from: https://www.cdc.gov/tb/topic/treatment/pregnancy.htm.

5. Sugarman J, Colvin C, Moran AC, Oxlade O. Tuberculosis in pregnancy: an estimate of the global burden of disease. The Lancet Global Health. 2014;2(12):e710-e6.

6. UN, editor International conference on population and development programme of action. International Conference on Population and Development; 1994.

7. Westoff CF, Bankole A. The potential demographic significance of unmet need. International Family Planning Perspectives. 1996:16-20.

8. WPR. World Population Review 2020 [Available from: https://worldpopulationreview.com/worldcities/addis-ababa-population.

9. Hubacher D, Trussell J. A definition of modern contraceptive methods. Contraception. 2015;92(5):420-1.

10. ANALYTICAL D. REVISING UNMET NEED FOR FAMILY PLANNING. 2012.

11. Cohen SA. London Summit puts family planning back on the agenda offers new lease on life for millions of women and girls. Guttmacher Policy Review. 2012;15(3):20-4.

12. EDHS. 2016 Demographic and Health Survey Key Findings. CSA; 2016.

13. UN. Trends in contraceptive use worldwide 2015. 2015.

14. Berhanu N, Haidar J. Modern contraceptive use and its associated factors among women taking anti retroviral therapy: Evidence from selected health institution of Addis Ababa, Ethiopia. East African Journal of Public Health. 2014;11(2):747-53.

15. Mohammed A, Woldeyohannes D, Feleke A, Megabiaw B. Determinants of modern contraceptive utilization among married women of reproductive age group in North Shoa Zone, Amhara Region, Ethiopia. Reproductive health. 2014;11(1):13.

16. Megabiaw B. Awareness and utilization of modern contraceptives among street women in NorthWest Ethiopia. BMC women's health. 2012;12(1):31.

17. Lakew Y, Reda AA, Tamene H, Benedict S, Deribe K. Geographical variation and factors influencing modern contraceptive use among married women in Ethiopia: evidence from a national population based survey. Reproductive health. 2013;10(1):52. 
18. Sedgh G, Hussain R, Bankole A, Singh S. Women with an unmet need for contraception in developing countries and their reasons for not using a method. Occasional report. 2007;37:5-40.

19. Sedgh G, Ashoford LS, Hussain R. Unmet need for contraception in developing countries: examine women's reasons for not using a method. The Guttmacher Institute; 2016.

20. EDHS. Ethiopia Demographic and Health Survey. Addis Ababa, Ethiopia and Calverton, Maryland, USA: central statistics agency and ORC macro. 2011.

21. Gebre G, Birhan N, Gebreslasie K. Prevalence and factors associated with unmet need for family planning among the currently married reproductive age women in Shire-Enda-Slassie, Northern West of Tigray, Ethiopia 2015: a community based cross-sectional study. Pan African Medical Journal. 2016;23(1).

22. Genet E, Abeje G, Ejigu T. Determinants of unmet need for family planning among currently married women in Dangila town administration, Awi Zone, Amhara regional state; a cross sectional study. Reproductive health. 2015;12(1):42.

23. Ajong AB, Njotang PN, Yakum MN, Essi MJ, Essiben F, Eko FE, et al. Determinants of unmet need for family planning among women in Urban Cameroon: a cross sectional survey in the Biyem-Assi Health District, Yaoundé. BMC women's health. 2015;16(1):4.

\section{Tables}


Table 1

Sociodemographic characteristics and Contraceptive utilization among Women on Tuberculosis Treatment in Selected Health Facilities in Addis Ababa,

Ethiopia. $(\mathrm{N}=309)$ *

\begin{tabular}{|c|c|c|c|}
\hline \multirow[t]{2}{*}{ Variable } & \multicolumn{2}{|c|}{ Contraceptive Utilization } & \multirow[t]{2}{*}{ P-Value** } \\
\hline & Yes 50(16.18\%) & No259(83.81\%) & \\
\hline \multicolumn{4}{|l|}{ Residency (N=309) } \\
\hline Urban N (\%) & $41(16.3)$ & 211(83.7) & \multirow[t]{2}{*}{0.929} \\
\hline Rural N (\%) & $9(18.8)$ & $48(84.2)$ & \\
\hline \multicolumn{4}{|l|}{ Age } \\
\hline $18-22$ & $4(5.2 \%)$ & $73(94.8 \%)$ & \multirow[t]{3}{*}{0.001} \\
\hline $23-33$ & $29(19.6 \%)$ & $119(80.4 \%)$ & \\
\hline $34-49$ & $17(20.2 \%)$ & 67(79.8\%) & \\
\hline \multicolumn{4}{|l|}{ Educational Status } \\
\hline Illiterate & $8(16.0 \%)$ & $42(84.0 \%)$ & \multirow[t]{4}{*}{0.25} \\
\hline Reading and writing & $7(28.0 \%)$ & $18(72.0 \%)$ & \\
\hline Elementary & $8(11.0 \%)$ & $65(89.0 \%)$ & \\
\hline Secondary and higher & $27(16.8 \%)$ & $134(83.2 \%)$ & \\
\hline \multicolumn{4}{|l|}{ Occupation (N=309) } \\
\hline Unemployed & $32(19.3)$ & $134(80.7)$ & \multirow[t]{2}{*}{0.111} \\
\hline Employed and Other & 18(12.6) & $125(87.4)$ & \\
\hline \multicolumn{4}{|l|}{ Monthly Income in birr } \\
\hline$<=420$ & $26(17.1 \%)$ & $126(82.9 \%)$ & \multirow[t]{4}{*}{0.23} \\
\hline $421-732$ & $7(7.9 \%)$ & $82(92.1 \%)$ & \\
\hline 733-1172 & $12(22.6 \%)$ & $41(77.4 \%)$ & \\
\hline 1173-3499 & $5(33.3 \%)$ & $10(66.7 \%)$ & \\
\hline \multicolumn{4}{|l|}{ Marital Status } \\
\hline Single & $17(9.8 \%)$ & $157(90.2 \%)$ & \multirow[t]{4}{*}{0.001} \\
\hline Married & $28(32.2 \%)$ & $59(67.8 \%)$ & \\
\hline Separated & $0(0.0 \%)$ & $5(100.0 \%)$ & \\
\hline Divorced & $5(21.7 \%)$ & $18(78.3 \%)$ & \\
\hline
\end{tabular}




\begin{tabular}{|c|c|c|c|}
\hline Widowed & $0(0.0 \%)$ & $20(100.0 \%)$ & \\
\hline \multicolumn{4}{|l|}{ Union } \\
\hline Yes & 28 (33.3) & $56(66.7 \%)$ & \multirow[t]{2}{*}{0.001} \\
\hline No & $22(9.8 \%)$ & $203(90.2 \%)$ & \\
\hline \multicolumn{4}{|c|}{ Number of living children } \\
\hline No Child & $15(7.7 \%)$ & $179(92.3 \%)$ & \multirow[t]{3}{*}{0.001} \\
\hline $1-3$ & $29(31.2 \%)$ & $64(68.8 \%)$ & \\
\hline$\geq 4$ & $6(27.3 \%)$ & $16(72.7 \%)$ & \\
\hline
\end{tabular}

* Of the 316 participants, 5 were pregnant and 2 were undecided on their pregnancy status this table is only for those using contraceptives

$P^{\star \star}$ value from Univariate analysis 
Table 2

FP Services linkage in TB Clinic among Women on Tuberculosis Treatment in Selected Health Facilities in Addis Ababa, Ethiopia. ( $\mathrm{N}=309)$

\begin{tabular}{|c|c|c|c|}
\hline \multirow[t]{2}{*}{ Variable } & \multicolumn{2}{|c|}{ Contraceptive Utilization } & \multirow[t]{2}{*}{$P *$-Value } \\
\hline & Yes & No & \\
\hline \multicolumn{3}{|l|}{ At the time of TB treatment were you told about FP services } & \multirow[t]{4}{*}{0.386} \\
\hline Yes & $26(18.6 \%)$ & $114(81.4 \%)$ & \\
\hline No & $23(15.0 \%)$ & $130(85.0 \%)$ & \\
\hline I don't know & $1(6.2 \%)$ & $15(93.8 \%)$ & \\
\hline \multicolumn{3}{|l|}{ Were you told about FP services at the HC or HF } & \multirow[t]{4}{*}{0.240} \\
\hline Yes & $28(20.0 \%)$ & $112(80.0 \%)$ & \\
\hline No & $20(13.3 \%)$ & $130(86.7 \%)$ & \\
\hline I don't know & $2(10.5 \%)$ & $17(89.5 \%)$ & \\
\hline \multirow[t]{2}{*}{ Were you referred for FP Services at other HC or HF } & & & \multirow[t]{5}{*}{0.233} \\
\hline & $23(19.5 \%)$ & $95(80.5 \%)$ & \\
\hline Yes & $26(15.2 \%)$ & $145(84.8 \%)$ & \\
\hline No & $1(5.0 \%)$ & $19(95.0 \%)$ & \\
\hline \multicolumn{3}{|l|}{ I don't know } & \\
\hline \multicolumn{3}{|l|}{ Do you know where you can get modern contraceptive* } & \multirow[t]{4}{*}{0.007} \\
\hline Yes & $43(20.2 \%)$ & $170(79.8 \%)$ & \\
\hline No & $3(20 \%)$ & $12(80 \%)$ & \\
\hline I don't know & $0(0 \%)$ & $1(100 \%)$ & \\
\hline \multicolumn{3}{|l|}{ Is this place closest to your home* } & \multirow[t]{3}{*}{0.017} \\
\hline Yes & $43(20.2 \%)$ & $170(79.8 \%)$ & \\
\hline No & $3(18.8 \%)$ & $13(81.2 \%)$ & \\
\hline
\end{tabular}

$\mathrm{FP}=$ Family planning, $\mathrm{TB}=$ Tuberculosis, $\mathrm{HC}=$ Health Center, $\mathrm{HF}=$ Health Facility

*P from univariate analysis

*25.8\% respondents were omitted for the last two questions as they were either single, widowed, separated or sexually inactive 
Table 3

Multivariate logistic regression among Women on Tuberculosis Treatment in Selected Health Facilities in Addis Ababa, Ethiopia. ( $\mathrm{N}=309)$

\begin{tabular}{|c|c|c|c|c|}
\hline \multirow[t]{2}{*}{ Variable } & \multicolumn{2}{|c|}{ Using Contraceptive } & \multirow[t]{2}{*}{ Crude OR $\quad(95 \% \mathrm{Cl})$} & \multirow{2}{*}{$\begin{array}{l}\text { Adjusted OR } \\
(95 \% \mathrm{Cl})\end{array}$} \\
\hline & Yes N(\%) & NO N(\%) & & \\
\hline \multicolumn{5}{|l|}{ Age } \\
\hline $18-22$ & $4(5.2 \%)$ & $73(94.8 \%)$ & $4.631(1.483,14.458)$ & $1.616(0.448,5.828)$ \\
\hline $23-33$ & $29(19.6 \%)$ & 119(80.4\%) & $1.041(.533,2.033)$ & $0.778(.360,1.681)$ \\
\hline $34-49$ & $17(20.2 \%)$ & $67(79.8 \%)$ & 1.00 & 1.00 \\
\hline \multicolumn{5}{|l|}{ Union } \\
\hline Yes & $28(33.3)$ & $56(66.7 \%)$ & $0.217(.115, .408)$ & $0.488(.223,1.068)$ \\
\hline No & $22(9.8 \%)$ & $203(90.2 \%)$ & 1.00 & 1.00 \\
\hline \multicolumn{5}{|l|}{ Parity } \\
\hline No child & $15(7.7 \%)$ & $179(92.3 \%)$ & 1.00 & 1.00 \\
\hline $1-3$ & $29(31.2 \%)$ & $64(68.8 \%)$ & $0.185(.093, .367)$ & $0.351(0.152,0.815)$ \\
\hline$\geq 4$ & $6(27.3 \%)$ & $16(72.7 \%)$ & $0.223(.076, .655)$ & $0.435(0.115,1.649)$ \\
\hline \multicolumn{5}{|c|}{$\begin{array}{l}\text { Do you know where you } \\
\text { can get }\end{array}$} \\
\hline \multicolumn{5}{|c|}{ Modern contraceptive } \\
\hline Yes & $43(20.2 \%)$ & $170(79.8 \%)$ & $0.265(.034,2.060)$ & $0.384(.032,4.55)$ \\
\hline No & $3(20 \%)$ & $12(80 \%)$ & $1.356(.132,13.969)$ & $1.344(.121,14.89)$ \\
\hline I don't know & $0(0 \%)$ & $1(100 \%)$ & 1.00 & \\
\hline \multicolumn{5}{|c|}{$\begin{array}{l}\text { Is this place closest to } \\
\text { your home }\end{array}$} \\
\hline Yes & $43(20.2 \%)$ & $170(79.8 \%)$ & $0.208(.086, .506)$ & $1.006(.252,4.019)$ \\
\hline No & $3(18.8 \%)$ & $13(81.2 \%)$ & 1.00 & 1.00 \\
\hline
\end{tabular}

Figures 


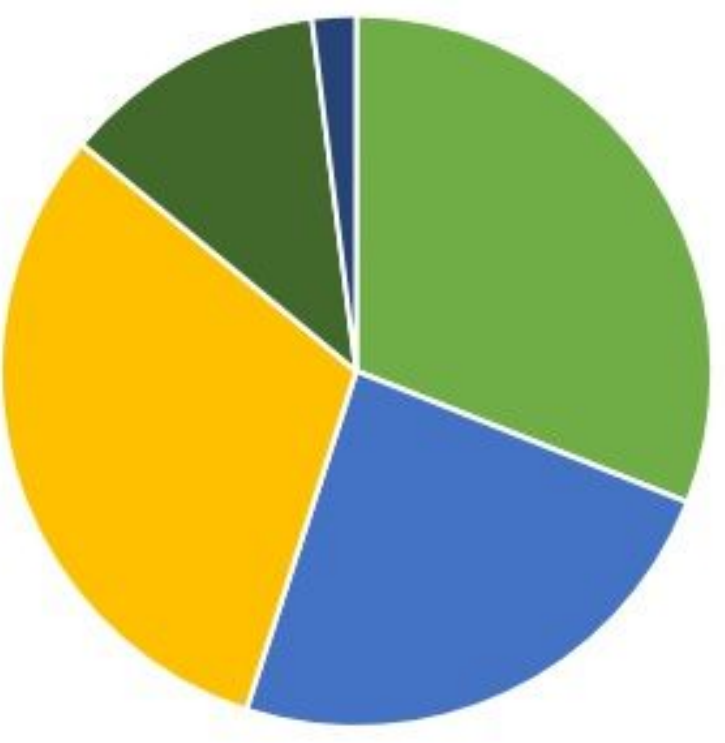

- Implant -Injection = IUCD =Oral Contra - Tubaligation

\section{Figure 1}

Type of contraceptive used among women on TB treatment in selected health facilities in Addis Ababa, Ethiopia.

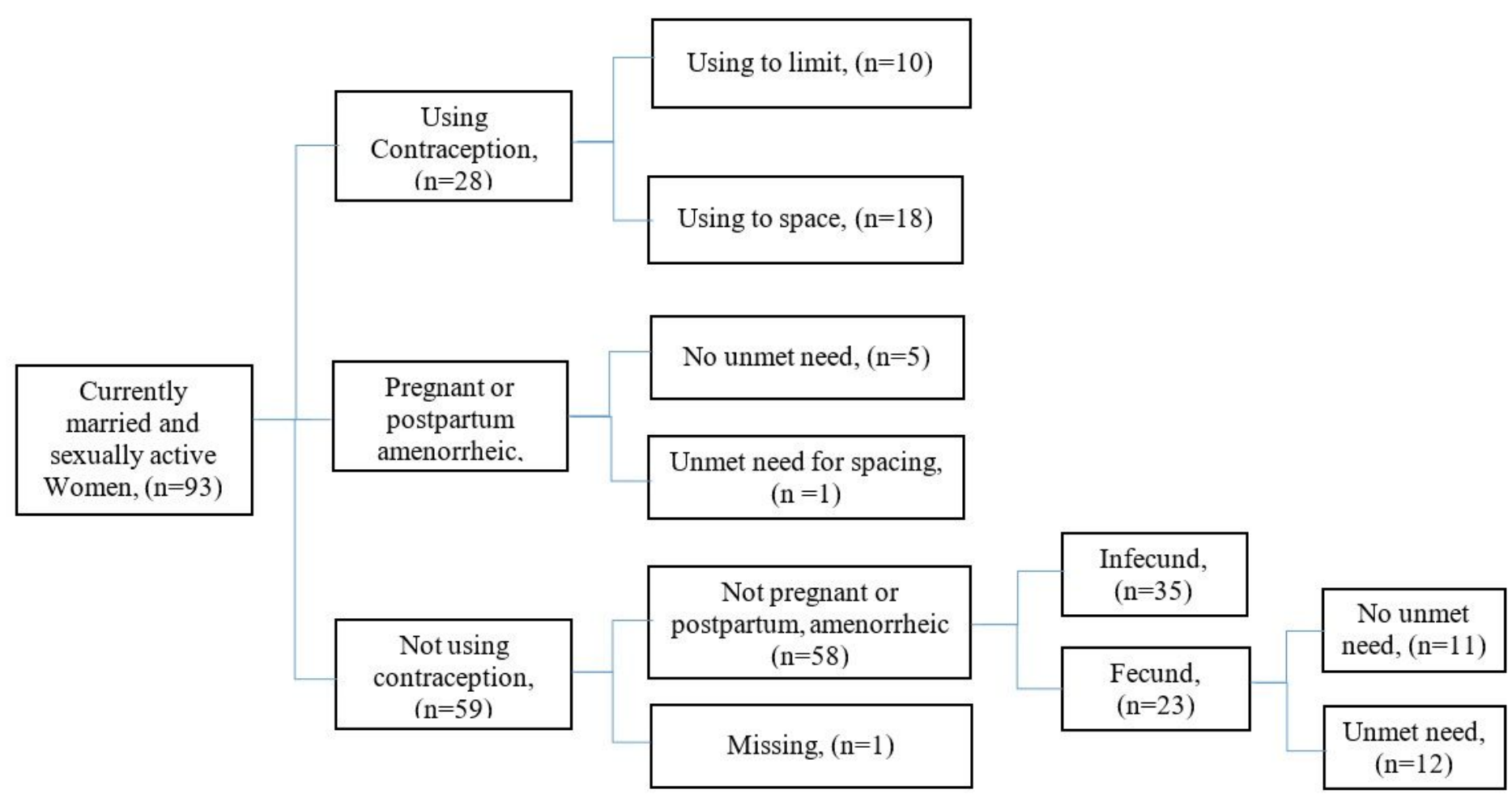

Figure 2 
Unmet Need among Married Women on Tuberculosis Treatment in Selected Health Facilities in Addis Ababa, Ethiopia. 